\title{
Study and optimization of freeze-drying cycles of a model probiotic strain
}

\author{
Verlhac, P. ${ }^{{ }^{*}}$; Vessot-Crastes, S. ${ }^{a}$; Degobert, G. ${ }^{a}$; Cogne, C. ${ }^{a}$; Andrieu, J. ${ }^{\mathrm{a}}$; Beney, \\ L. ' ; Gervais, P. \\ a Université de Lyon, Université Claude Bernard Lyon 1, Laboratoire d'Automatique et Génie des \\ Procédés (LAGEP), UMR CNRS 5007, Domaine de la Doua, 69100, Villeurbanne, France \\ ${ }^{\mathrm{b}}$ Univ. Bourgogne Franche-Compté, AgroSup Dijon, PAM UMR A 02.102. F-21000, Dijon, France \\ *E-mail of the corresponding author: pierre.verlhac@univ-lyon1.fr
}

\begin{abstract}
This work is based on the experimental study of the freeze-drying process to understand the impact of numerous factors on the survival rates of a model probiotic strain of Lactobacillus casei type. With the aim to find out if cell density in the matrix and survival rates are linked, we have studied the location of the cells after freeze drying inside a porous matrix composed of a lactose basis with a polymer, the polyvinylpyrrolidone (PVP) in various amounts. The best survival rate were obtained at slow freezing rate for a formulation containing $5 \%(\mathrm{~m} / \mathrm{V})$ of lactose and $5 \%(\mathrm{~m} / \mathrm{V})$ of PVP.
\end{abstract}

Keywords: Freeze-Drying; Freezing; Probiotics; L. Casei ATCC 393. 


\section{Introduction}

According to Food and Agriculture Organization of the United Nations and World Health Organization, probiotics are defined as "live micro-organisms which, when administered in adequate amounts, confer a health benefit on the host"[1]. Probiotics are generally temperature sensitive bacteria (with different degrees of sensitivity depending on the numerous strains), which loss a part of their viability and their favorable health properties during their dehydration processes and, next, during the storage and transport steps before their consumption. Many factors such as temperature, oxygen level, osmotic pressure and $\mathrm{pH}$ stresses have an important impact on their viability and, on their health promoting effect. Two types of methods are mainly used to stabilize and to maintain a long term activity level, namely the freezing and more or less soft drying techniques such as spraydrying, fluidized bed drying and freeze-drying. The freeze-drying is known as the method that usually leads to the best results in term of many quality factors of the freeze dried cake (viability rate, rehydration rate, etc.) despite various damaging effects generated by the freezing and sublimation/desorption phenomena (crystal growth; cryoconcentration, etc. $)^{[2]}$. Nevertheless, this method has the major inconvenient to lead to the highest operating costs due to the very severe operating conditions of this discontinuous process which has to be carried out at very low levels of temperature and total gas pressure. During this long and complex soft dehydration process, three phase changes are taking place so that the living bacteria have to endure numerous stresses more or less interdependent and deeply understood (thermal, osmotic, $\mathrm{pH}$, sub-cooling, intracellular crystallization...). Moreover, important differences exist between the different probiotic's species, sub-species and strains, particularly in terms of resistance to the severe process conditions generally encountered $^{[3]}$. This is why the main objective of our work was to establish a rational protocol of optimization of freeze-drying cycles with a model probiotic strain, easily adaptable to other bacteria. This protocol is based on the reduction of stress effects in order to obtain the highest survival rates. Firstly we studied the cell immobilization by adsorption or inclusion inside a porous matrix. We have chosen to investigate on a formulation constituted of lactose (a popular effective cryoprotectant known for not influencing the cells content) and polyvinylepyrrolidone (PVP) which is a polymer widely used in the pharmaceutical industry due to its interesting properties of stabilization ${ }^{[4]}$. Indeed, PVP has been already used as cryoprotectants and has a higher glassy transition (Tg') than most of the saccharides so that it can reduce the drying time by increasing the sublimation and desorption limit temperatures.The freezing protocol - especially the freezing rate -which could prove to be the key damaging step of the whole freeze-drying process, was investigated. Indeed, this step appeared to be the most lethal period for micro-organisms mainly because of osmotic phenomena occuring at the cell level. Then, we have investigated the influence of the total amount of each component in the formulation on the location of the bacteria in the solid matrix and on the survival rate. 
Verlhac, P.; Vessot-Crastes, S.; Degobert, G.; Cogne, C.; Andrieu, J.; Beney, L.; Gervais, P.

\section{Materials and Methods}

\subsection{Bacteria and growth conditions}

The strain Lactobacillus Casei ATCC® $393^{\mathrm{TM}}$ (Alliance Bio Expertise, Guipry, France) was rehydrated from the Kwik-Stik ${ }^{\circledR}$-containing the original dried strain- and then isolated on a MRS agar petri dish and finally incubated for $48 \mathrm{~h}$ at $37^{\circ} \mathrm{C}$. A single colony was collected from the plate and inoculated in 100mL MRS broth and finally incubated for $24 \mathrm{~h}$ at $37^{\circ} \mathrm{C}$ under orbital shaking (150 rpm). Next a $1 \%$ diluted solution was prepared in 150 $\mathrm{mL}$ MRS broth and incubated under orbital shaking (150 rpm) during 30h.

\subsection{Formulation composition}

Once the stationary phase was obtained, the bacterial suspension was centrifuged at $7000 \mathrm{~g}$ during 10min at ambient temperature and next washed twice with saline buffer solution $(0,85 \% \mathrm{NaCl}(\mathrm{m} / \mathrm{V}))$. Then the pellet was suspended again before processing. Various solutions were prepared with a Kollidon ${ }^{\circledR 3} 3$ (PVP) and monohydrate lactose basis in the range of concentration from $1 \%$ to $10 \%(\mathrm{~m} / \mathrm{V})$ or only with the saline buffer (Table 1 ).

Table 1. Index of the formulation composition

\begin{tabular}{ccc}
\hline Nomenclature & $\begin{array}{c}\text { Weight Lactose } \\
\text { composition }(\mathbf{m} / \mathbf{V})\end{array}$ & $\begin{array}{c}\text { Weight Kollidon }{ }^{\circledR 30} \\
\text { composition }(\mathbf{m} / \mathbf{V})\end{array}$ \\
\hline K5 & $0 \%$ & $5 \%$ \\
L5 & $5 \%$ & $0 \%$ \\
KL10-5 & $5 \%$ & $10 \%$ \\
KL1-1 & $1 \%$ & $1 \%$ \\
KL5-5 & $5 \%$ & $5 \%$ \\
KL10-10 & $10 \%$ & $10 \%$ \\
\hline
\end{tabular}

\subsection{Freezing and thawing protocol}

Immediately after formulation, the solutions were poured into $6 \mathrm{~mL}$ glass vials and next frozen from ambient temperature up to $-45^{\circ} \mathrm{C}$ at different freezing rates, namely: $0.5 ; 1 ; 2$; $5^{\circ} \mathrm{C} / \mathrm{min}$ and a very fast rate by immersing directly the vials into liquid nitrogen. We investigated the effect of cold thermal stresses at the slowest rates by introducing, before the freezing step, a temperature plateau at $5^{\circ} \mathrm{C}$ during $1 / 2 \mathrm{~h}$. Then, the temperature was maintained during $2 \mathrm{~h}$ before the thawing step which was performed by immersing the vials into distilled water at $37^{\circ} \mathrm{C}$ and next, immediately diluted for the enumeration.

\subsection{Freeze-Drying process}

A slow freezing rate was chosen, namely at $0.5^{\circ} \mathrm{C} / \mathrm{min}$ with a temperature plateau at $5^{\circ} \mathrm{C}$. The sublimation step (primary drying period) was performed slowly under vacuum at 150 
Pa and around $-40^{\circ} \mathrm{C}$. Next, the desorption step (secondary drying period) was achieved during $24 \mathrm{~h}$ at $20^{\circ} \mathrm{C}$ under $50 \mathrm{~Pa}$. All the vials were closed immediately inside the freezedryer chamber, hermetically sealed and finally stored at $4^{\circ} \mathrm{C}$. Lyophilisates were rehydrated quickly at $20^{\circ} \mathrm{C}$ by addition of an adequate amount of saline buffer solution for enumeration of viable bacteria.

\subsection{Enumeration and residual moisture}

The rehydrated powder and the thawed solution were decimally diluted and next incubated at $37^{\circ} \mathrm{C}$ during $72 \mathrm{~h}$ to enumerate the colony forming unit (CFU). Every enumeration was conducted in triplicate. The moisture contents in the freeze-dried vials were determined by the classical the Karl-Fisher method (860 KF Thermoprep - Metrohm). Samples of the freeze-dried cake (between 10 and $20 \mathrm{mg}$ ) were introduced into the Karl-Fisher oven at $150^{\circ} \mathrm{C}$.

\section{Results and Discussion}

\subsection{Effect of the addition of PVP and lactose on the bacterial viability}

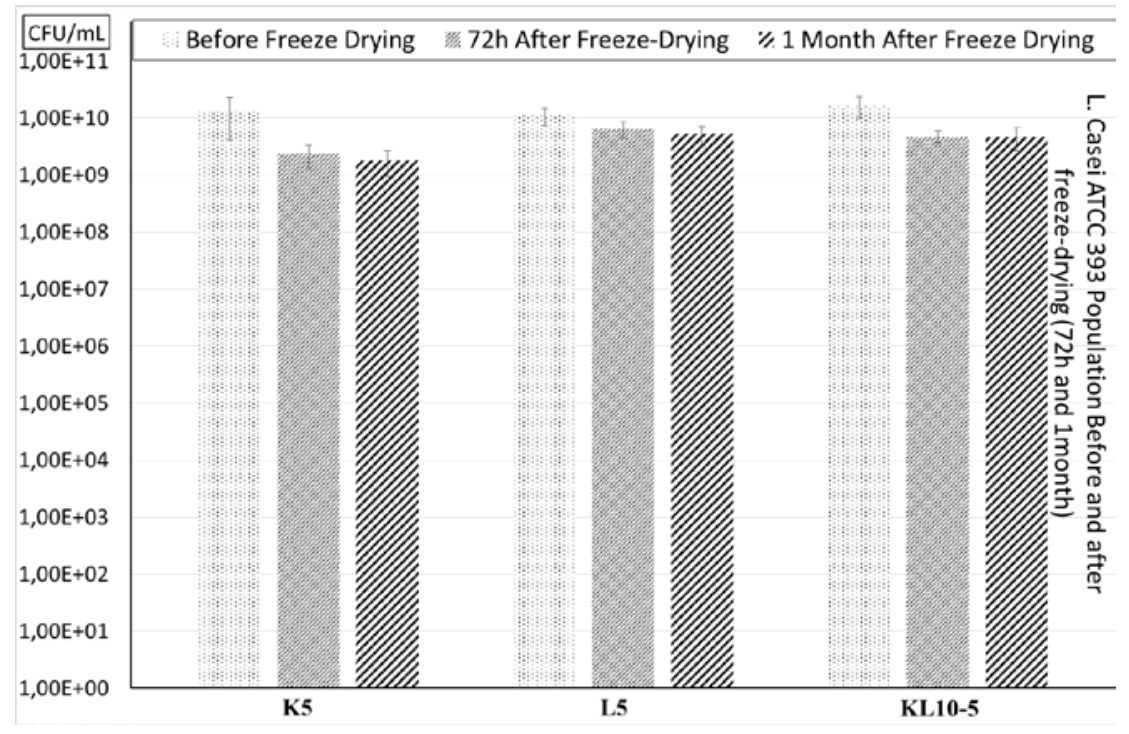

Fig. 1 Effect of polymer PVP and lactose on the viability of Lactobacillus Casei after freeze drying.

Bacterial suspensions were mixed with pure lactose (Ref. L5) or pure polymeric solution (Ref. K5) or a mixture of different concentration of these two components (KL10-5 Cf Table 1). No significant differences on bacterial viability were observed between these formulations after freeze-thawing. These results show that the presence of this polymer had not detrimental effects on the survival of bacteria, so that we concluded that it could be used as protectant of our formulation. After freeze-drying, survival rates exhibited light 
Verlhac, P.; Vessot-Crastes, S.; Degobert, G.; Cogne, C.; Andrieu, J.; Beney, L.; Gervais, P.

differences between the different formulations of protectants (Fig.1). Just after process the concentration of viable bacteria decreases more when the polymer was the only protectant (K5). With the lactose formulation (L5), the survival of bacteria appeared to reach the highest values, even after one month of storage. However, the solution KL10-5 seemed to present the highest stability after one month of storage even if the survival ratio right after the end of the whole freeze-drying process was slightly affected. This means that a formulation that combined lactose and PVP components could offer a high stabilizing effect for the storage. This favorable effect could be explained by the matrix vitrification phenomenon which could entrap and protect the cells during the process, by reducing the mechanical stresses induced by ice crystal growing, but also during the storage, by increasing the stability due to the high glassy transition values of the $\mathrm{PVP}^{[5]}$.

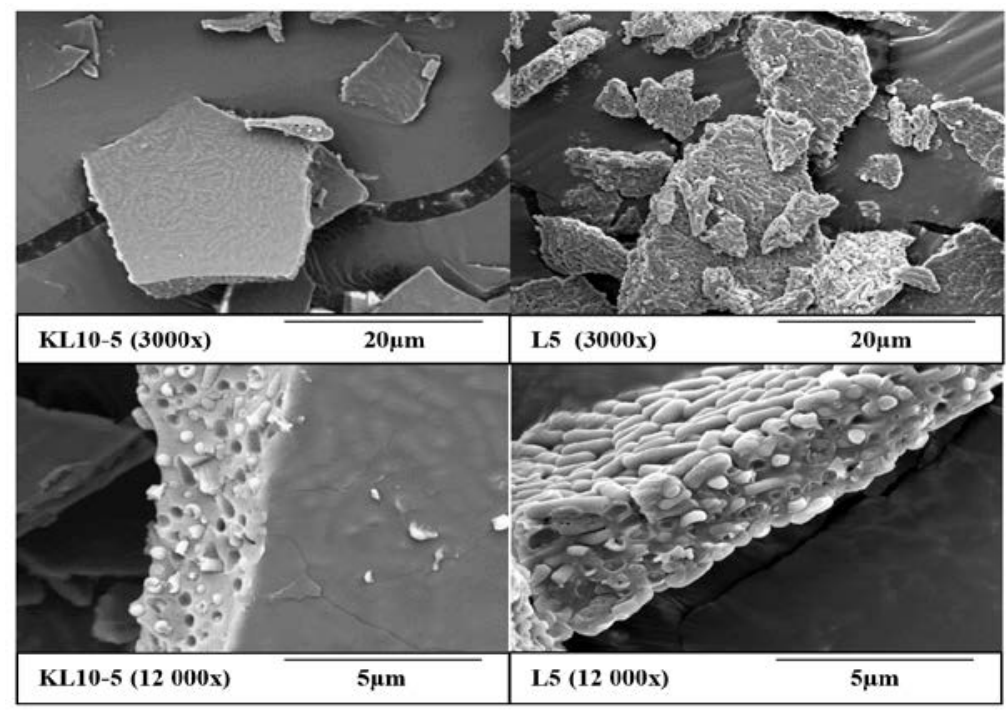

Fig. 2 SEM photography of the repartition of dried L. Caseï ATCC 393 in the porous matrix based on lactose and Kollidon ${ }^{\circledR} 30$ or only lactose.

Next, SEM photographs (Fig.2) allowed to observe the position of the bacteria located in the freeze-dried solid matrix. In the case of formulation KL10-5, the bacteria did not appeared at the pore's surface and seemed included inside the solid part of the freeze-dried matrix. On the contrary, for the $\mathbf{L} 5$ formulation, as the relative amount of dry matter of lactose was smaller, the bacteria covered the pore's surface of the matrix. This behaviour could explain why the survival rate was lower with the KL10-5 formulation than with the L5 one. When the matrix was fixed during the freezing step, the bacteria may have suffered high local pressure levels due to Ostwald ripening phenomena during and just after the crystallization step. However, on a long time scale, the morphology and the structure of the solid matrix of the mixture could allow a higher survival ratio due to the formation of a 
thick solid layer which can prevent the diffusion of water and oxygen up to the cells ${ }^{[6]}$.Experiments were carried out to find out the less damaging freezing kinetics. It appeared that a slow freezing rate around $0.5^{\circ} \mathrm{C} / \mathrm{min}$ with a stabilization temperature step between 0.5 and $1 \mathrm{~h}$ before the starting of the freezing at $5^{\circ} \mathrm{C}$ led to the best survival rate, with no significant reduction of viable bacteria. This could be related to a cold stress response from the bacteria, because, in reaction to the stress, the cells may produce Cold Shock Proteins allowing them to prevent damages ${ }^{[7]}$. Other hypothesis has been proposed on the dehydration rate of the cells, due to slow osmotic pressure variations preventing intracellular water crystallization due to cell water exit ${ }^{[8]}$. These results have to be compared with experimental data showing the influence of nucleation temperature.

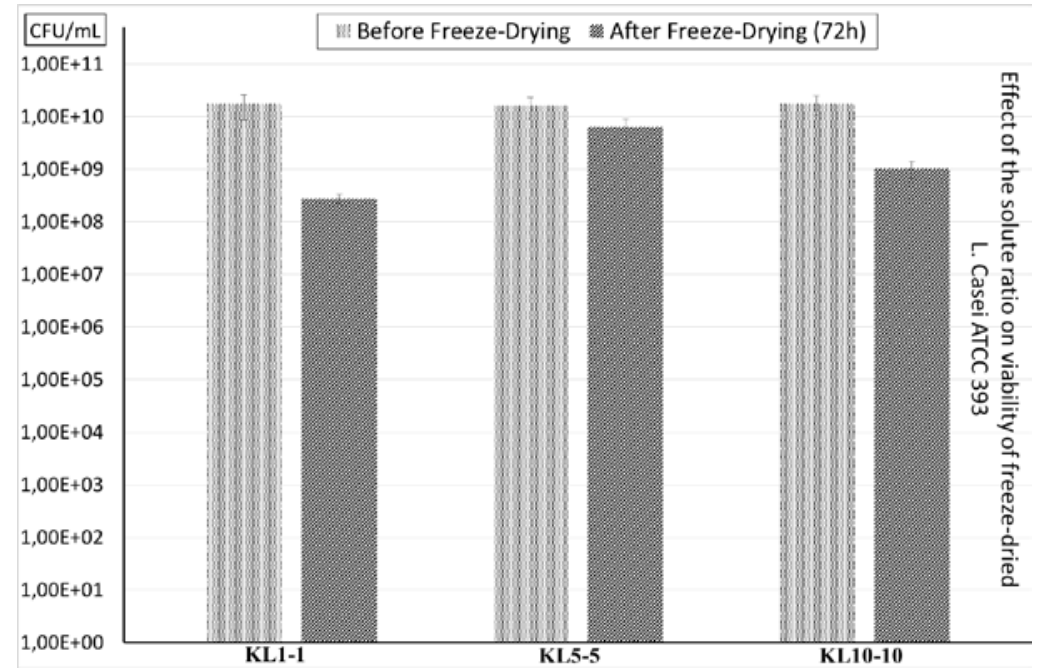

Fig. 3 Effect of the amount of solute on the viability of L. Caseï ATCC 393

\subsection{Influence of the amount of solute protectants on the bacteria location and viability}

After observing the differences in the repartition of bacteria and morphology of the solid matrix with SEM pictures (as mentioned above), we characterized the influence of the amount of dry matter on the final viability of bacteria. We have chosen to investigate, at the same weight ratio, two extreme compositions and one central composition of the scale (Table 1). Some of the freeze-dried cakes were observed by SEM and the others were rehydrated for plate counting. For the lyophilisate that contained the lower solute concentration (KL1-1), we obtained approximately a 2-log reduction of the viable bacteria after freeze-drying while less than 0.5-log reduction for the KL5-5 and around 1.2-log reduction for the KL10-10 (Fig.3). The SEM photograph of Fig. 4 showed that the freezedried matrix network formed by KL1-1 formulation was very thin with a high density of bacteria. 
Verlhac, P.; Vessot-Crastes, S.; Degobert, G.; Cogne, C.; Andrieu, J.; Beney, L.; Gervais, P.

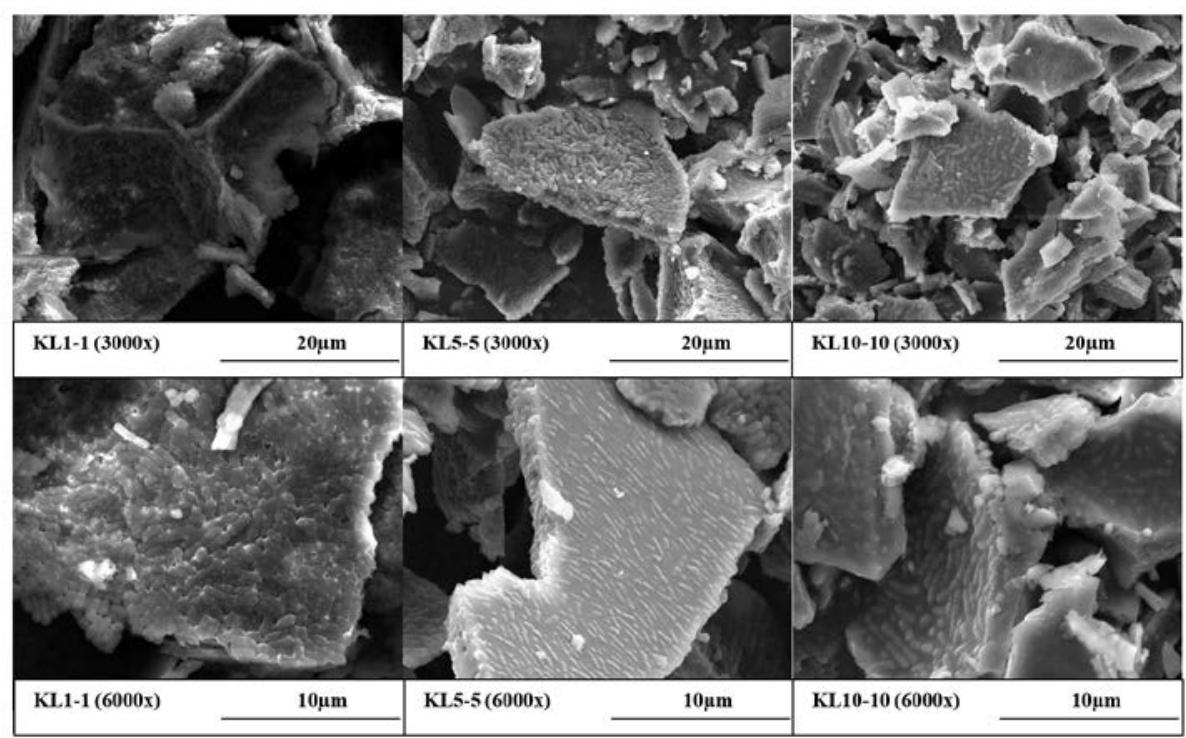

Fig. 4 SEM photography of the repartition of dried L. Caseï ATCC 393 in the porous matrix based on extreme lactose and Kollidon ${ }^{\circledR 3} 3$ content.

The physical aspect with KL1-1 at macroscopic scale was not enough consistent and the freeze-dried cake was difficult to analyze due to its fragility. Other experiments and photographs carried out with only buffered solutions and with only bacteria led to very low survival rates. The differences in bacterial location and on matrix structure for KL5-5 and KL10-10 formulation were more difficult to find out. In both cases we could observe a thick structure recovering the cells. Nevertheless, differences in the viability seemed to be linked to the mass ratio between dried excipients (lactose and PVP) and dried bacteria. In the case of low amounts of excipients, the bacteria were directly exposed to water during the rehydration process. Indeed, the rehydration rate had probably a great influence on the final viability ratio of the cells and the amount of solute exerted probably an important buffer effect on the mechanisms of water transfer to the cells. In another hand, a too important content of excipients could unbalance the osmotic equilibrium of bacteria with their surrounding solution during the formulation and freezing steps and, by the way, could generate too important water flows crossing the cells walls which resulted to important cell death ratios or viability losses ${ }^{[8]}$. That's why a balance should be established between too low content of protectant resulting in a loss of efficiency and a too high content, providing high stresses to the cells. Nevertheless, the KL5 formulation presented the highest survival ratios with this soft freeze-drying protocol. Then, our forecoming work will focus on this formulation with the aim of parameters optimization and design space set up. 


\section{Conclusion}

This study presents the effect of composition and of freezing parameters of a PVP Kollidon ${ }^{\circledR} 30$ and lactose based formulation on the viability of a L. Casei strain during a standard freeze-drying cycle. The polymer and cells were considered as compatible since no significant reduction was observed on the viability of the probiotic strain, even after one month of storage. The SEM photographs showed that the type and the concentration of solute in the cells preparation have an important impact on the cells location inside the freeze-dried matrix and, consequently, on the survival ratio. The KL5-5 formulation led to the best bacteria survival ratio with less than 0.5 log reduction after a standard freezedrying cycle. Nevertheless, it is still difficult to conclude on the mechanisms explaining the best observed viability at this composition. These results indicated that the PVP can be used with this probiotic strain, and, moreover, it may preserve the viability of bacteria for long time storage in the freeze-dried form. Our next study will focus on the process optimization parameters and the design space set up allowing a viable and stable freeze-dried product.

\section{References}

[1] Food and Agriculture Organization of the United Nations and World Health Organization, Eds., Probiotics in food: health and nutritional properties and guidelines for evaluation. Rome 2006.

[2] J. Barbosa et al., "Comparison of spray drying, freeze drying and convective hot air drying for the production of a probiotic orange powder," Journal of Functional Foods, vol. 17, pp. 340-351, août 2015.

[3] O. F. Celik and D. J. O’Sullivan, "Factors influencing the stability of freeze-dried stress-resilient and stress-sensitive strains of bifidobacteria,” Journal of Dairy Science, vol. 96, no. 6, pp. 3506-3516, juin 2013.

[4] Y. Furushima, K. Ishikiriyama, Y. Ueno, and H. Sugaya, "Analysis of the state of water in polyvinylpyrrolidone aqueous solutions using DSC method," Thermochimica acta, 2012.

[5] J. H. Crowe, S. B. Leslie, and L. M. Crowe, "Is vitrification sufficient to preserve liposomes during freeze-drying?,” Cryobiology, vol. 31, no. 4, pp. 355-366, Aug. 1994.

[6] G. Lemetais, S. Dupont, L. Beney, and P. Gervais, “Air-drying kinetics affect yeast membrane organization and survival,” Appl Microbiol Biotechnol, vol. 96, no. 2, pp. 471-480, Oct. 2012.

[7] J. R. Broadbent and C. Lin, "Effect of Heat Shock or Cold Shock Treatment on the Resistance of Lactococcus lactis to Freezing and Lyophilization,” Cryobiology, vol. 39, no. 1, pp. 88-102, août 1999.

[8] P. Gervais, P. A. Marechal, and P. Molin, "Effects of the kinetics of osmotic pressure variation on yeast viability,” Biotechnol. Bioeng., vol. 40, no. 11, pp. 1435-1439, décembre 1992. 